\title{
Studying permafrost by integrating satellite and in situ data in the northern high-latitude regions
}

\author{
Nureldin A. A. Gido ${ }^{1,2}$ (D) Mohammad Bagherbandi ${ }^{1,2} \cdot$ Lars E. Sjöberg $^{1,2} \cdot$ Robert Tenzer $^{3}$
}

Received: 28 October 2017 / Accepted: 27 February 2019 / Published online: 7 March 2019

(c) The Author(s) 2019

\begin{abstract}
There is an exceptional opportunity of achieving simultaneous and complementary data from a multitude of geoscience and environmental near-earth orbiting artificial satellites to study phenomena related to the climate change. These satellite missions provide the information about the various phenomena, such as sea level change, ice melting, soil moisture variation, temperature changes and earth surface deformations. In this study, we focus on permafrost thawing and its associated gravity change (in terms of the groundwater storage), and organic material changes using the gravity recovery and climate experiment (GRACE) data and other satellite- and ground-based observations. The estimation of permafrost changes requires combining information from various sources, particularly using the gravity field change, surface temperature change, and glacial isostatic adjustment. The most significant factor for a careful monitoring of the permafrost thawing is the fact that this process could be responsible for releasing an additional enormous amount of greenhouse gases emitted to the atmosphere, most importantly to mention carbon dioxide $\left(\mathrm{CO}_{2}\right)$ and methane that are currently stored in the frozen ground. The results of a preliminary numerical analysis reveal a possible existence of a high correlation between the secular trends of greenhouse gases $\left(\mathrm{CO}_{2}\right)$, temperature and equivalent water thickness (in permafrost active layer) in the selected regions. Furthermore, according to our estimates based on processing the GRACE data, the groundwater storage attributed due to permafrost thawing increased at the annual rates of 3.4, 3.8, 4.4 and $4.0 \mathrm{~cm}$, respectively, in Siberia, North Alaska and Canada (Yukon and Hudson Bay). Despite a rather preliminary character of our results, these findings indicate that the methodology developed and applied in this study should be further improved by incorporating the in situ permafrost measurements.
\end{abstract}

Keywords Climate change $\cdot$ Permafrost $\cdot$ Gravity $\cdot$ Grace $\cdot$ Greenhouse gas

\section{Introduction}

The permafrost is frozen soil, sediment or rock that remains under $0{ }^{\circ} \mathrm{C}$ for at least two consecutive years (Brown et al. 1998). There are different layers, of which frozen ground represents just one portion. The active layer is the surface layer of soil that is seasonally frozen in winter and thaw each summer, causing relatively large surface movements at the order of centimetres, or even decimetres over periods of

Nureldin A. A. Gido

Nureldin.Gido@hig.se; naag@kth.se

1 Faculty of Engineering and Sustainable Development, University of Gävle, SE-80176 Gävle, Sweden

2 Division of Geodesy and Satellite Positioning, Royal Institute of Technology (KTH), SE-10044 Stockholm, Sweden

3 Department of Land Surveying and Geo-Informatics, Hong Kong Polytechnic University, Kowloon, Hong Kong months (seasonal variations) and years (cf. Biskaborn et al. 2015). The talik is an unfrozen ground layer that lies below the active layer and above the permafrost. As seen in Fig. 1, the permafrost is found in large parts of the Northern Hemisphere, mostly in Siberia, Canada, Alaska, Greenland, and the northern parts of Sweden and Norway (Schaefer et al. 2012). Climate warming is more rapid in the northern highlatitude regions and causes thawing of the permafrost over a great expanse of area in the Arctic region (Liu et al. 2010). This has major impact on the arctic water cycle, as ground ice melts and flow pathways between layers and groundwater increase. The permafrost thaw is a very complex phenomena that can in some cases lead to the water storage change that could be detected in gravity variations. Soils in the Arctic permafrost region are estimated to hold about twice as much carbon as the atmosphere (Hugelius et al. 2011). As previously frozen permafrost organic carbon thaws and decomposes, there is a potential positive feedback between 
Fig. 1 Permafrost distribution in the northern high latitudes. Image credit: Philippe Rekacewicz, 2005, UNEP/GRIDArendal maps and graphics library based on International Permafrost Association (1998) circumpolar active-layer permafrost system (CAPS), version 1.0. https://www.wundergrou nd.com/resources/climate/melti ng_permafrost.asp

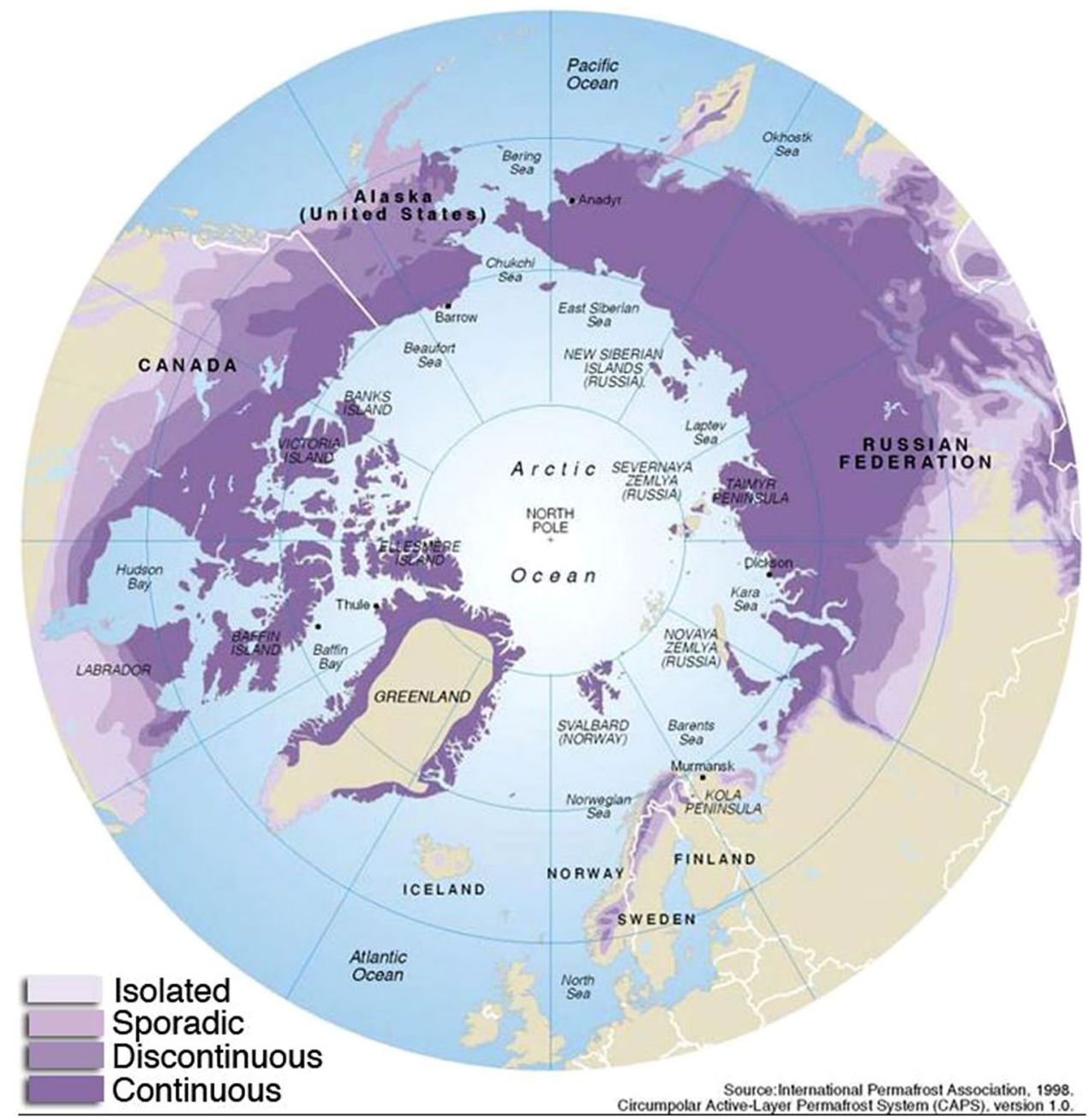

the permafrost thaw and the global warming if the Arctic turns from a net sink to a net source of carbon. Hence, studying thawing permafrost is very important, not only from a perspective of localized geo-hazard such as erosion, damage to buildings and infrastructure, but also with respect to its possible global impact due to greenhouse gas emissions.

The permafrost regions are one of the most heavily impacted regions by the climate change. Studying the permafrost might allow us to investigate a long-term development of the earth's shape interior, gravity field, climate change and assessment of its impact. The permafrost thawing has been investigated using satellite gravimetry techniques (GRACE; Tapley et al. 2004) in many publications in addition to streamflow analyses (e.g. Sjöberg et al. 2013) that use thermal sensors in boreholes that measure the thickness of the active permafrost layer. For example, Velicogna et al. (2012) studied the permafrost thawing using GRACE data in the Lena river basin (cf. Muskett and Romanovsky 2009, 2011; Vey et al. 2013) and Shabanloui and Müller (2015) conducted a similar study for the whole Siberia (cf. Chao et al. 2011). They determined the water storage changes attributed to the permafrost thawing using GRACE data and compared their results with various hydrological effects such as the soil moisture and the river run-off. The importance of the permafrost for the earth's ecosystem (in terms of the released carbon dioxide and nitrogen into the atmosphere due to thawing of permafrost active layer) was also recognized by Treat et al. (2014), Yang et al. (2013), Schaefer et al. (2011) and others.

In this study, we propose a unique approach to study the permafrost thawing using satellite data, e.g. GRACE and other satellite- and ground-based observations in order to determine surface changes/deformations in the northern highlatitude region. For this purpose, the mass variations due to the permafrost thawing are estimated in terms of the groundwater level change in the study region. By using the outcomes of this study, we try to find geophysical mechanisms being the most plausible, e.g. the thawing of permafrost and the glacial isostatic adjustment (GIA). The satellite-based data, e.g. GRACE, is collected from low-orbited dedicated missions, which provide homogeneous and global coverage. However, these data suffer from inherent data processing problems and 
need to be addressed properly in order to achieve reliable and accurate results. Another task to be tackled is finding an optimal method for data noise filtering (especially for GRACE data (Sjöberg and Bagherbandi 2017, Sect. 8.7) and meteorological signals (rain, snow water, surface water, etc.). How to extract the permafrost signal from satellite data is an important challenge here. For example, studying temporal gravity changes and their relation with the permafrost using GRACE data requires the knowledge about the land uplift (GIA) (Peltier 2004; Ågren and Svensson 2007) and the continental hydrological signal (GLDAS, Global Land Data Assimilation System; Rodell et al. 2004). The potential of the GRACE for detecting mass changes related to different phenomena has been studied before and during the first years of its operation, for instance, by Wahr et al. $(1998,2004)$ and Swenson et al. (2003). It is important to mention here that the gravity data collected by GRACE require applying a smoothing procedure in order to reduce the effects of errors present in the short-wavelength component. Various methods have been proposed to filter the GRACE data (cf. Swenson and Wahr 2006; Wouters and Schrama 2007; Klees et al. 2008; and Kusche et al. 2009). Among them, we could mention the most commonly applied isotropic Gaussian (Wahr et al. 1998) or the non-isotropic (Han et al. 2005) filters. However, none of these methods accounts for a correlated noise in data.

In this study, we estimate water storage changes due to permafrost thawing (not dry permafrost, bare rocks, thawing) using satellite gravimetry methods in the study region. Therefore, studying the contribution of some disturbing signals such as land uplift (GIA), surface water and surface snowfall on the signal detected by GRACE is necessary. Moreover, we also address the determination of the permafrost-related near-surface mass changes (due to permafrost thawing) and their correlation with released greenhouse gases.

\section{Monitoring near-surface mass change by GRACE}

Today, the most successful data for studying temporal changes in the gravity field stem from the very long record of satellite laser ranging for very long wavelengths (Moore et al. 2005), and more recently also from the accurate gravity-dedicated satellite mission GRACE for shorter/more regional phenomena (cf. Lemoine et al. 2007). GRACE is appropriate for studying some geodynamic phenomena such as GIA, climate change and permafrost thawing, because these phenomena are related to a mass change and consequently propagated into gravity field change. Moreover, these changes occur over relatively large areas, thus having prevailing long-wavelength spatial pattern that could be detected by GRACE that could measure secular gravity changes related to near-surface mass changes.
A satellite disturbing potential model ( $T$ ) typically consists of numerical values for the potential coefficients $\left(C_{n m}\right)$. A time-dependent change in the earth's gravity field due to mass transport causes changes in the harmonic coefficients. These changes can be described by the residual spherical harmonic coefficients $\Delta C_{n m}$ that are obtained after subtracting the mean value from monthly solutions. The absolute disturbing potential and its changes are then described by

$\left(\begin{array}{c}T \\ \Delta T\end{array}\right)=\frac{G M}{R} \sum_{n=0}^{n_{\max }}\left(\frac{R}{r}\right)^{n+1} \sum_{m=-n}^{n}\left(\begin{array}{c}C_{n m} \\ \Delta C_{n m}\end{array}\right) Y_{n m}(\theta, \lambda)$,

$\Delta C_{n m}=C_{n m}-\bar{C}_{n m}$,

where $\bar{C}_{n m}$ is the mean value of spherical harmonics over time, $\Delta T$ is either the change in $T$ from one time to another or the difference between $T$ at one time and the time average of $T, G M$ is the geocentric gravitational constant (i.e. the product of Newton's gravitational constant and the total mass of the earth including the atmosphere), $R$ the Earth's mean radius, $n_{\max }$ is maximum degree of harmonic expansion, $(r, \theta, \lambda)$ are, respectively, the geocentric radius, colatitude and longitude of the computational point, $Y_{n m}$ is the surface spherical harmonic of degree $n$ and order $m$, and

$\Delta C_{n m}=\left\{\Delta C_{n m}\right\}_{\text {surface mass }}+\left\{\Delta C_{n m}\right\}_{\text {solid mass }}$.

As seen in Eq. (2), the residual spherical harmonic coefficients $\Delta C_{n m}$ consist of the direct gravitational contribution of the surface mass $\left\{\Delta C_{n m}\right\}_{\text {surface mass }}$ and the additional contribution of the surface mass load $\left\{\Delta C_{n m}\right\}_{\text {solid mass }}$ that deforms the underlying solid earth. Hence, we have (cf. Wahr et al. 1998)

$$
\begin{aligned}
{\left[\begin{array}{c}
\left\{\Delta C_{n m}\right\}_{\text {surface mass }} \\
\left\{\Delta C_{n m}\right\}_{\text {solid mass }}
\end{array}\right]=} & {\left[\begin{array}{c}
3 /[4 \pi R \bar{\rho}(2 n+1)] \\
3 k_{n} /[4 \pi R \bar{\rho}(2 n+1)]
\end{array}\right] } \\
& \iint_{\sigma} \Delta \sigma(\theta, \lambda) Y_{n m}(\theta, \lambda) d \sigma,
\end{aligned}
$$

where $\Delta \sigma(\theta, \lambda)$ is the surface density change (mass/area), and $\bar{\rho}$ is the earth's mean density. The load Love numbers $k_{n}$ are modelled based on some available earth model (e.g. Farrell 1972; Sun and Sjöberg 1999; Bevis et al. 2016).

By repeating GRACE satellite tracks for measuring the gravity field, the linear least-squares regression analysis can be applied to determine temporal changes (i.e. secular trend) of the disturbing potential (cf. Sjöberg and Bagherbandi 2017, Chapt. 2). The regression equations are given by:

$a+b t_{i}+\sum_{j=1}^{J}\left(c_{j} \cos \omega_{j} t_{i}+d_{j} \sin \omega_{j} t_{i}\right)=\Delta T_{i}-\varepsilon_{i} ; \quad i=1, \ldots, n$, 
where $\omega_{j}=2 \pi / T_{j}$, periods are denoted by $T_{j}$ and $J$ is the number of periodic signals included in the adjustment. Considering a linear regression (i.e. $a+b t_{i}=\Delta T_{i}-\varepsilon_{i}$ ) in time $\left(t_{i}\right)$ with observation equations (Eq. 4 ), the secular change of the spherical harmonic coefficients $\left(C_{n m}^{*}\right)$ is given by:

$C_{n m}^{\cdot}=\frac{1}{4 \pi} \iint_{\sigma} \mathbf{b} Y_{n m}(\theta, \lambda) d \sigma$.

where $\mathbf{b}$ is a matrix which includes the computed secular trends using Eq. (4).

Sjöberg and Bagherbandi (2017, Sect. 8.7) showed that estimated rates of a secular trend in the gravity field do not differ significantly when either including or not periodic terms in the analyses. Using $C_{n m}$, the secular changes of the disturbing potential and gravity disturbance can be described up to some limited degree $n_{\max }$ as follows (Sjöberg and Bagherbandi 2017, Chapters 3 and 8 )

$\dot{T}=\frac{G M}{R} \sum_{n=0}^{n_{\max }}\left(\frac{R}{r}\right)^{n+1} \sum_{m=-n}^{n} C_{n m} Y_{n m}(\theta, \lambda)$

$\dot{\delta g}=\frac{G M}{R^{2}} \sum_{n=0}^{n_{\max }}\left(\frac{R}{r_{P}}\right)^{n+2}(n+1) \sum_{m=-n}^{n} C_{n m} Y_{n m}(\theta, \lambda)$,

According to Sjöberg and Bagherbandi (2017), Chapter 8, the near-earth's surface mass change rate can be determined from

$\dot{\kappa} \approx \frac{\bar{\rho} R}{3} \sum_{n=0}^{n_{\max }} \frac{2 n+1}{1+k_{n}} \sum_{m=-n}^{n} C_{n m} Y_{n m}(\theta, \lambda)$.

The monthly mass changes propagate into changes in the earth's gravity field. For computational purposes, these mass changes are often considered as being concentrated in a very thin layer of water thickness changes. Their vertical extent is measured in centimetres of the equivalent water thickness. To get a general picture of the lateral distribution of mass anomalies, one may also represent the secular trend of the disturbing potential in terms of the total water storage (TWS) changes. Using GRACE data, we estimate the secular trend of TWS change according to Wahr et al. (1998) by

$\mathrm{TWS}=\frac{R \bar{\rho}}{3 \rho_{w}} \sum_{n=0}^{n_{\max }} \frac{2 n+1}{1+k_{n}} \sum_{m=-n}^{n} C_{n m}^{.} Y_{n m}(\theta, \lambda)$

where $\rho_{w}$ is the water density.

\section{GRACE data and processing procedure for permafrost studies}

There are different products for GRACE, monthly, weekly and 10-day solutions provided by several analysis centres. The three main analysis centres are: Center for Space Research (CSR) at the University of Texas at Austin, Jet Propulsion Laboratory (JPL) in Pasadena and GeoForschungsZentrum (GFZ) in Potsdam. In addition, there are solutions from the University of Bonn (ITG), the Centre National d'Etudes Spatiales (CNES) in Toulouse and the Technical University Delft (DEOS Mass Transport model). For this study, we used the Release-05 GRACE level-2 monthly time-variable gravity field products from CSR over the period from August 2002 to May 2016 provided in terms of the fully normalized geopotential spherical harmonic coefficients to determine the TWS changes. These GRACE data were filtered and corrected for GIA, hydrological signal and glaciers melting in order to estimate the equivalent water height secular trend due to the permafrost thawing layer (EWHP). The filtering and correction procedures are briefly summarized in the next sections.

\section{Noise filtering}

The epoch-wise GRACE gravity field models require smoothing in order to reduce the effects of errors at short wavelengths. The GRACE data contain coloured noise that shows up in the provided spherical harmonic coefficients (Kusche et al. 2009). Basically, truncating the spherical harmonic series at long wavelengths, where the noise is not yet significant, yields the loss of an unacceptably high portion of the signal. The noise can usually be described by systematic/correlated stripping patterns. The reason for this is the mission geometry, as GRACE twin-satellites fly in the same near-polar orbital plane, and the inter-satellite ranging observable used in gravity modelling transforms into a distinct along-track sensitivity (Sjöberg and Bagherbandi 2017, Chap. 8). Deficiencies in de-aliasing models cause an anisotropic error that cannot be removed, for instance, by applying the Gaussian isotropic filter. Instead, the decorrelation method should be used in the post-processing of GRACE data, such as those discussed by Kusche (2007), Klees et al. (2008) and Kusche et al. (2009). Kusche's technique uses a priori synthetic model of the observation geometry for the de-correlation. In this study, we used Kusche's technique (DDK2 filer) to remove stripping patterns in the CSR GRACE data (see Joud et al. 2017).

\section{GIA correction}

In the study region, the earth's crust is rising continuously since the last glacial maximum due to de-loading of the 
former ice sheet. The process of ongoing relaxation due to the viscoelastic structure of the earth mantle is known as glacial isostatic adjustment (GIA). The land uplift is well documented from various studies (see e.g. Ekman 1991 and Peltier and Argus 2015 for historical reviews). Although GIA is a well-known process for more than a century, it still attracts the attention of geoscientific community due to its extended number of applications in the understanding, modelling, measuring and correcting for different phenomena related to the present issues of interest to the global society.

GIA causes changes in the earth's gravity field. The estimation of mass changes, obtained from GRACE data, in terms of the equivalent water thickness will not be correct without removing the GIA contribution. For this purpose, the land uplift rate should be converted to equivalent land uplift water height (ELUWH) by

$\mathrm{ELUWH}=\frac{\bar{\rho}}{3 \rho_{w}} \sum_{n=0}^{n_{\max }} \frac{2 n+1}{1+k_{n}} \sum_{m=-n}^{n} h_{n m} Y_{n m}(\theta, \lambda)$,

where $h$ is the land uplift rate.

\section{Hydrological corrections}

The hydrological monthly data from the global land data assimilation system (GLDAS) hydrological model over the period from January 2002 to May 2016 with $0.25 \times 0.25$ or $1.0 \times 1.0$ arc-degree spatial resolution can be extracted (Chen et al. 1996; Koren et al. 1999) via the Hydrology Data and Information Service Center (HDISC). GLDAS provides global information on land surface status (e.g. surface temperature, soil moisture, precipitation, river run-off, etc.) with three-hour or monthly temporal resolutions based on integrating satellite and ground-based observation data. Four land surface models are currently used by GLDAS, specifically Mosaic, NOAH, CLM and VIC (see Rodell et al. 2004). In this study, we used the NOAH model according to Chao et al. (2011), which has a total of four soil layers thickness (i.e. 0-10, 10-40, 40-100 and 100-200 cm). The precipitation and other hydrological parameters are very important because their effect on the water storage change is significant in the study area (see Fig. 5). The regression analysis has been used to calculate the secular trend of the hydrological data (similar to Eq. 4).

\section{Ice-melting correction}

For extracting the water storage change due to permafrost thawing, the effect of ice-mass loss of Greenland ice sheet triggered by regional warming should be removed from GRACE data. The rate of ice elevation change from 2003 to 2012 was computed by using altimeter surveys from NASA's ATM flights during 2003-2012 supplemented with high-resolution ice, cloud and land elevation satellite (ICESat) data from 2003 to 2009 (cf. Khan et al. 2014). The result shows that large areas in the centre of the Greenland ice sheet (GrIS) have few or no measurements during the period between 2010 and 2012 . Thus, the variability in the elevation change rate during this period is not fully covered in the elevation change estimates. To overcome this problem, the ENVISAT radar altimeter measurements have been used from April 2009 to March 2012. This dataset is obtained from the RA-2 SGDR product (see Khan et al. 2014), while the standard (SGDR) corrections for atmospheric propagation and tides were applied. Observables provided by a radar altimetry suffer from problems with the slope effect; therefore, in this study, we did not use data around the edge of the GrIS (from the ice margin and about $50-70 \mathrm{~km}$ inland). While other studies have made attempts to merge laser altimetry data with radar altimetry data, here we used the elevation change rates estimated from ENVISAT and laser altimetry separately and combined these rates. Icemelting results using the above-mentioned data are presented in Fig. 2. Similar to Eq. (10), the correction due to equivalent ice-melting water height was computed.

The near-earth surface mass variations obtained from GRACE data are related to hydrological (water) variations. These variations are, however, attributed not only to the permafrost thawing, but also to the precipitation and run-off variations. Therefore, the secular trend of equivalent water height due to permafrost thawing (EWHP) was estimated by removing the signals triggered by the GIA and hydrological contributions from the obtained TWS(Eq. 9). This procedure is described by the following scheme:

$$
\begin{aligned}
\mathrm{EWHP}= & \underset{\text { GRACE }}{\mathrm{TWS}}-\mathrm{EWHP}-\underset{\text { snow }}{\mathrm{WS}}-\underset{\text { canopy }}{\mathrm{WS}} \\
& -\underset{\text { run }- \text { off }}{\mathbf{W S}}-\underset{\text { SoilMoisture }}{\mathrm{WS}}-\underset{\text { ice - melting }}{\mathrm{WS}},
\end{aligned}
$$

where ELUWH is the land uplift water equivalent height (Eq. 10), $\mathrm{WS}_{\text {snow }}$ is the water storage due to the water equivalent of snow, $\mathrm{WS}_{\text {canopy }}$ is the canopy water storage, $\mathrm{WS}_{\text {run - off }}^{\text {. }}$ is the water storage variation due to run-off river, $\mathrm{WS}_{\text {SoilMoisture }}$ denotes the water storage due to soil moisture variation (accumulated soil moisture internally from different layers) and $\mathrm{WS}_{\text {ice - melting }}$ is water storage from the ice melting in Greenland (for this study).

\section{Results}

Using the static 30-day GRACE gravity field solutions over the period from 2002 to 2016, the residual spherical harmonic coefficients were determined according to Eq. (1b), and consequently the disturbing potential changes were computed according to Eq. (1a). The spectral rates of the gravity 


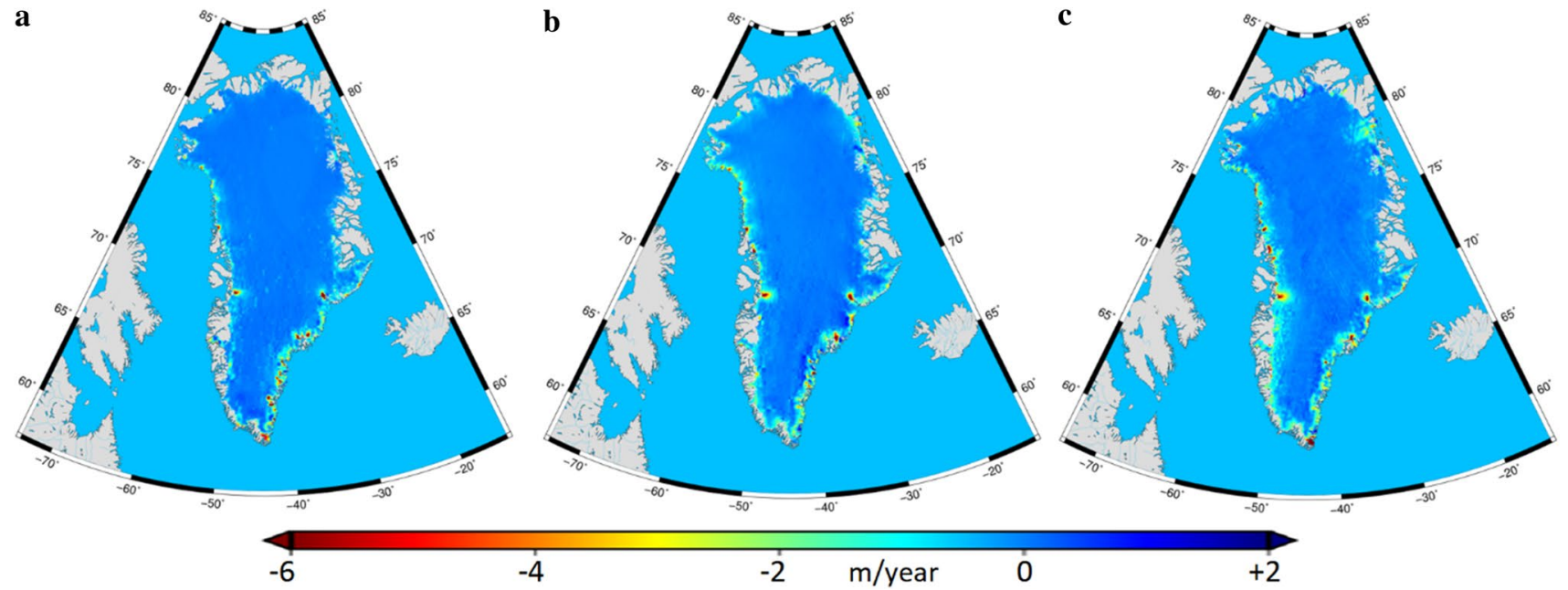

Fig. 2 Observed elevation change rates (m/year) in Greenland obtained from ICESat mission during periods: a from April 2003 to April 2006, b from April 2006 to April 2009 and $\mathbf{c}$ from April 2009 to April 2012

field change (in terms of $C_{n m}$ ) were then determined using a time-series analysis according to Eq. (5). After obtaining the values of $\dot{C}_{n m}$, the total water storage (TWS ) was computed from Eq. (9). The resulting secular rates were then filtered and corrected for the contributions of GIA, hydrology (such as precipitation, soil moisture, river run-off and canopy using GLDAS data), and ice melting (in Greenland) in order to be used for calculating the equivalent water height trend due to permafrost thawing (EWHP).

The obtained EWHP from the GRACE data is verified using in situ data, e.g. land surface temperature from GLDAS (Rodell et al. 2004 and Swenson et al. 2003), borehole data and carbon dioxide changes (e.g. using NASA's EOS Aqua mission, see https://mirador.gsfc.nasa.gov/colle ctions/AIRX3C2M_005.shtml). We expected to obtain a correlation between the rate of groundwater change (obtained from GRACE data) and in situ data. The distribution of permafrost monitoring stations (boreholes) in the study region is shown in Fig. 6b. More information about these stations can be found through the global terrestrial network for permafrost through http://gtnpdatabase.org/, where the following important data are available: surface temperature, ground temperature, active layer thickness, surface soil moisture and air temperature.

To remove the effect of GIA from the secular rate of total water storage (TWS) obtained from GRACE, we used the ICE-6G (VM5a) model (Peltier and Argus 2015). This model shows the rate of radial displacements (Fig. 3a). Red and yellow areas in the figure indicate rising due to removal of the ice sheets. In ICE-6G (VM5a), the most recently available GPS observations have been employed. For this purpose, the land uplift rate was converted to equivalent land uplift water height (ELUWH) using Eq. (10). The result of the ELUWH is presented in Fig. $3 b$.

The resulting secular rates of TWS from the CSR GRACE data centre are shown in Fig. 4a. We further removed ELUWH (Fig. 4b) from TWS. Figure 4b shows the resulting values of TWS without the presence of GIA,
Fig. 3 Regional maps of: a the land uplift rate obtained from the ice model ICE-6G (VM5a) and $\mathbf{b}$ the equivalent land uplift water height change (ELUWH)
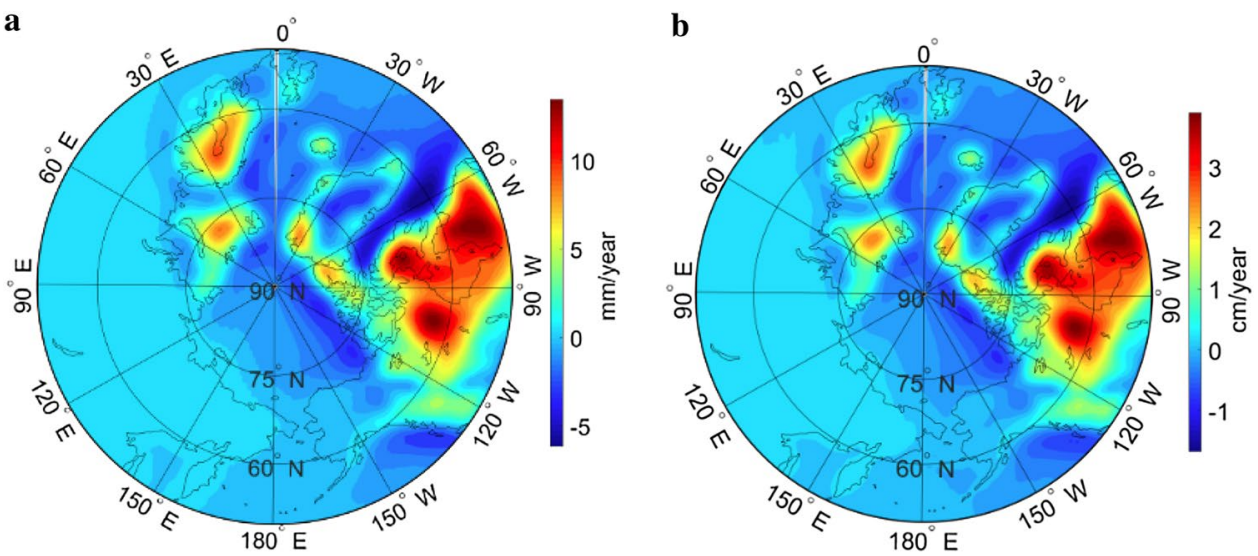
and especially it can be seen that the land uplift signal is removed in Laurentia and Fennoscandia.

Since GRACE detects all hydrological changes as well as the water level change due to the permafrost, we further modelled and removed the hydrological signals (in terms of the equivalent water height) from the secular rates of the TWS. In order to filter out the non-permafrost signals, we used GLDAS hydrological model. In Fig. 5, we illustrate the hydrological parameters adopted in our computation, particularly soil moisture, precipitation (snow), canopy and river run-off that were obtained from the GLDAS model using Eq. (4). It is worth mentioning that most of the hydrological signals, such as precipitation, are hidden implicitly in the soil moisture variations, i.e. one part of the precipitation is converted to the river run-off water masses, while the other part is evaporated. Therefore, we were able to filter out the effect of precipitation by subtracting the soil moisture rate from the TWS rate. The result after subtracting the hydrological signals is shown in Fig. 6a.

Table 1 shows the summary of different corrections to the total water storage computed from GRACE data, i.e. GIA, hydrological signal and glaciers melting. The results show that the gravitational effect of some corrections (such as river run-off and canopy) is in general at least one order of the magnitude smaller than the EWHP.

As emphasized by Lawrence et al. (2015), the large-scale permafrost thaw predicted by GRACE results in significant soil drying due to an increased drainage following permafrost thaw, even though permafrost domain water inputs are projected to rise. This phenomenon could clearly be recognized in our result shown in Fig. 6a. The results show positive trend for the water level after the permafrost layer thawing in selected stations (about 3-4 cm/year; see Table 2 for more details). This was confirmed in previous studies by Brown et al. (2000), Frauenfeld et al. (2004), Zhang et al. (2005) and Lemke et al. (2007). They reported a notable increase in Siberian permafrost active layer since 1950s. Muskett and Romanovsky (2009) demonstrated an increase in the groundwater storage in Lena, Ob' and Yenisei basins in Siberia. Wu and Zhang (2010) reported a similar trend at the Tibetan Plateau. An increasing water level can also be caused by the topography/slope of surrounding areas of the stations, as more water masses are transported from higher to lower elevations after the permafrost layer thawing. For this reason, a much more relevant is the study of the lowland permafrost in unconsolidated sediments that are not ice-rich and aquifer can infiltrate additional water after permafrost thaw. It usually stores considerable amounts of water in form of ground ice. However, the permafrost thaw processes are quite complex even in lowland regions. Depressions form after the melt of ground ice/water and thermokarst lakes form (Phillips et al. 2003). These lakes usually undergo a cyclic growth and drainage. Ice wedges and related ice wedge polygons are also very important source of ground ice/water in these environments. However, in some locations the type of the permafrost contains significant amounts of ground ice of very different origins (French and Hugh 2013, Chapter 7). It can happen that the thawed soil/sediment is already saturated with water, and then an increase in water storage might not be possible in some areas, leading to a mass decrease, as is the case in the southern parts of Alaska and Greenland (e.g. in the areas with negative equivalent water height trend in Fig. 6a).

\section{Comparison with greenhouse gases and temperature changes}

The permafrost regions cover almost $80 \%$ of the study area, while locally reaching a maximum thickness up to about $1 \mathrm{~km}$ (Yakutia in central Siberia). Therefore, it is expected that the permafrost thawing plays a significant role in the climate change and mass transportation (cf. Steffen et al. 2012; Shabanloui and Müller 2015). Greenhouse gases emissions due to the permafrost thawing further change the ecosystem (Treat et al. 2014; and Yang et al. 2013). A large amount of carbon was stored in the permafrost by a process that took thousands of years. Mixing of soil layers due to repeated
Fig. 4 Regional maps of the equivalent water height secular trends (TWS) obtained from the CSR GRACE data over the period from August 2002 to May 2016: a before and $\mathbf{b}$ after removing the equivalent land uplift water height change
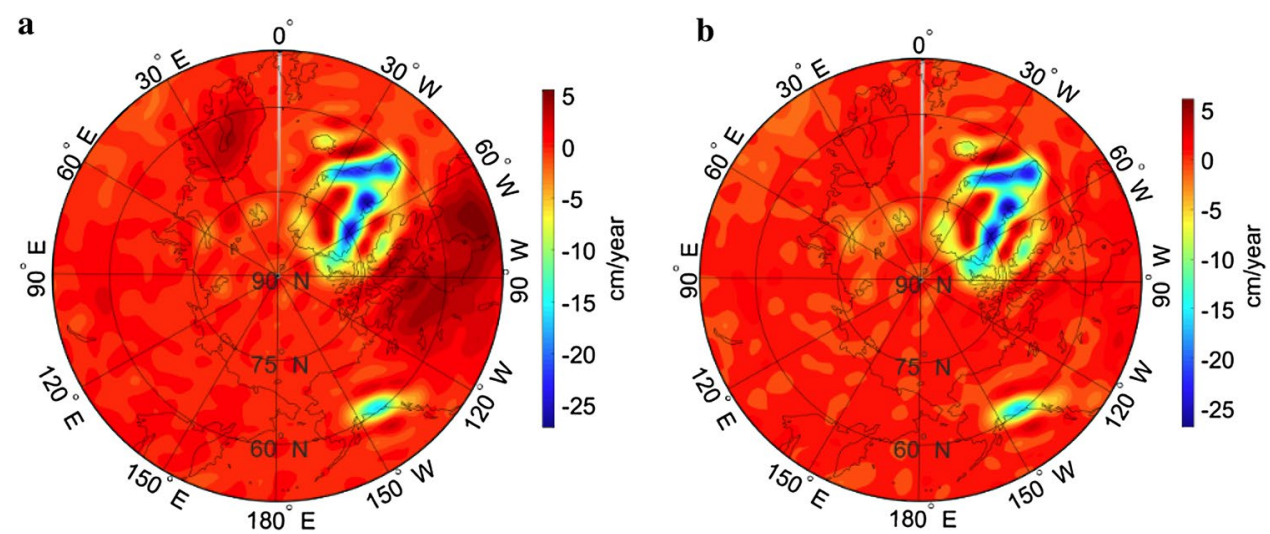
Fig. 5 Regional maps of the equivalent water height secular trends according to the GLDAS/NOAH land hydrological model due to hydrological contributions in terms of the water equivalent of $\mathbf{a}$ soil moisture ( $\mathrm{WS}_{\text {SoilMoisture }}$ ), b snow $\left(\mathrm{WS}_{\text {snow }}\right.$ ) and ice melting ( $\mathrm{WS}_{\text {ice - melting }}$ ), c canopy (WS canopy $_{\text {ice }}$ ), $\mathbf{d}$ river run-off $\left(\mathrm{WS}_{\text {run - off }}^{\text {canopy }}\right)$ and e soil surface temperature
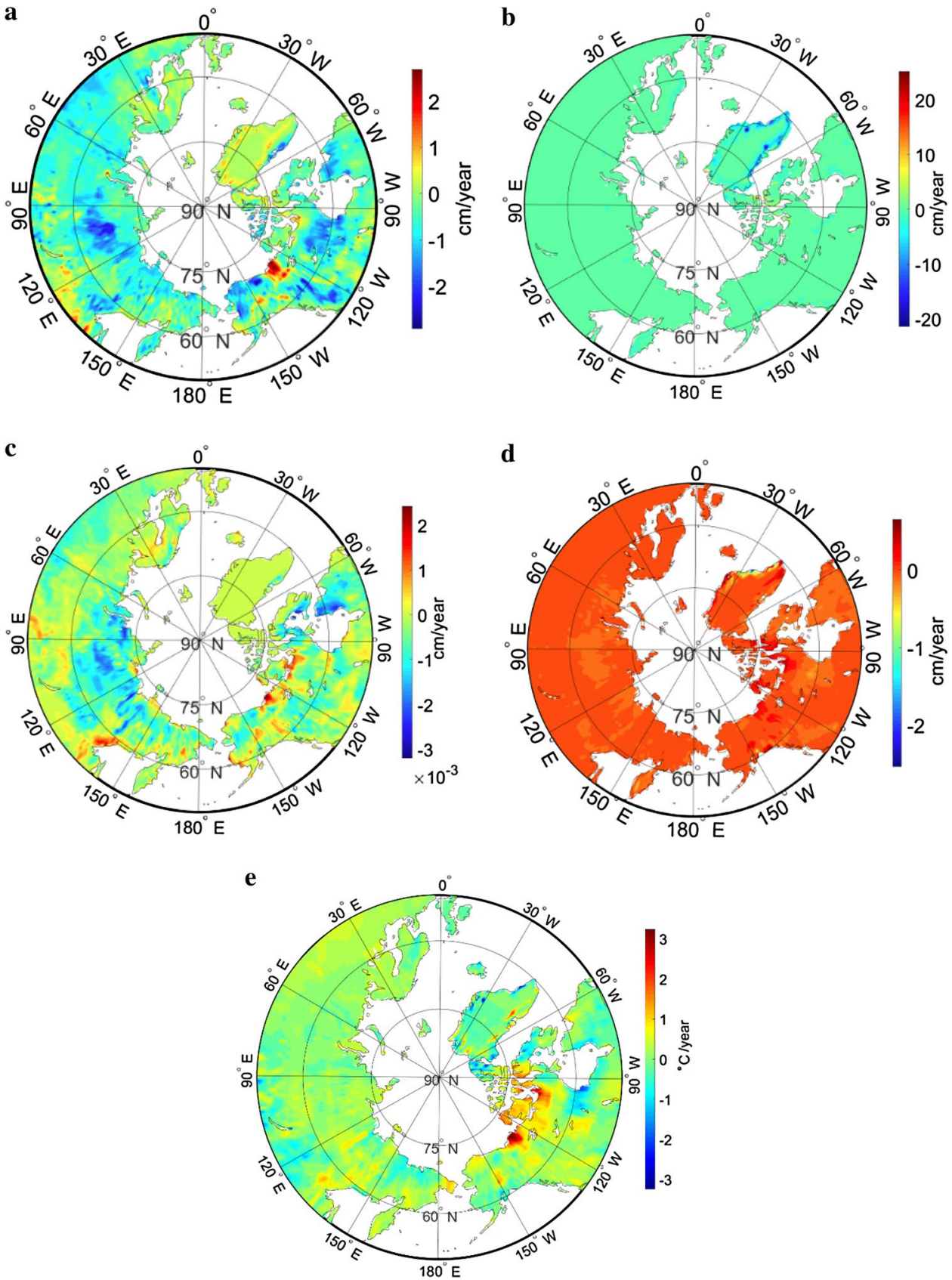

freeze-thaw processes (Cryoturbation) in the active layer accelerates the burial process by mixing the carbon-rich organic soil from the surface down to the permafrost horizon (Zech et al. 2008). Warming in high latitudes leads to a soil warming and permafrost thaw, which results in carbon decomposition by soil microbes (Schuur et al. 2009) and releasing the greenhouse gases as carbon dioxide and methane (Koven et al. 2011). Studies and observations indicate a notable widespread permafrost thawing in the Northern Hemisphere (Lemke et al. 2007). For example, Osterkamp (2007) reported an increasing trend in the permafrost temperature by $2-3{ }^{\circ} \mathrm{C}$ over the last two decades at depth of
$20 \mathrm{~m}$ and also at depths up to $20 \mathrm{~m}$ increased $0-2{ }^{\circ} \mathrm{C}$ in Canada (cf. Smith et al. 2004 and Lemke et al. 2007). Similar results presented in Siberia by Lemke et al. (2007) show the temperature increases between 0.3 and $2.8^{\circ} \mathrm{C}$ at depths up to $10 \mathrm{~m}$.

For this study, we used the monthly gridded $2.5 \times 2.0$ arcdegree data about greenhouse gases emissions provided by NASA (https://mirador.gsfc.nasa.gov/collections/AIRX3 C2M_005.shtml). In particular, we used data of the AIRS mid-tropospheric carbon dioxide collected by the atmospheric infrared sounder (AIRS) and the advanced microwave sounding unit (AMSU) instruments on board of the Aqua 


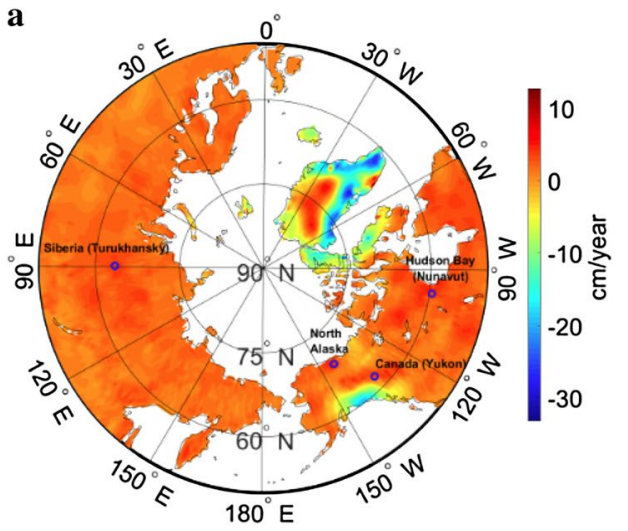

Fig. 6 a Regional map of the equivalent water height secular trend due to permafrost thawing after removing hydrological contribution obtained using GRACE and ICESat data and GLDAS/NOAH land hydrological model during 2002/08-2016/05 in the northern high-lat-

Table 1 Statistics of total water storage (TWS), GIA, hydrological signal and glaciers melting. Unit: $\mathrm{cm} /$ year

\begin{tabular}{|c|c|c|c|c|}
\hline & Max & Mean & Min & $\begin{array}{l}\text { Standard } \\
\text { deviation }\end{array}$ \\
\hline $\begin{array}{l}\text { Total water storage } \\
\left(\text { TWS }_{\text {GRACE }} \text { ) }\right.\end{array}$ & 6.1 & -0.3 & -27.8 & 3.2 \\
\hline GIA correction (ELUWH) & 4.0 & 0.1 & -1.8 & 0.8 \\
\hline Snow $\left(\mathrm{WS}_{\text {snow }}\right)$ & 27.5 & 0.6 & -22.6 & 5.3 \\
\hline Canopy $\left(\mathrm{WS}_{\text {canopy }}\right) \times 10^{-4}$ & 25 & -3.2 & 33 & 5.7 \\
\hline River run-off $\left(\mathrm{WS}_{\text {run - off }}\right)$ & 0.7 & 0.0 & -2.6 & 0.1 \\
\hline Soil Moisture $\left(\mathrm{WS}_{\text {SoilMoisture }}\right)$ & 2.8 & -0.4 & -3.0 & 0.6 \\
\hline Ice melting $\left(\mathrm{WS}_{\text {ice - melting }}\right)$ & 25.9 & -0.2 & -22.1 & 1.2 \\
\hline
\end{tabular}

satellite in mole fraction units (PPM in volume). These data cover the period of 110 months from 1 January 2003 to 1 February 2012. AIRS is a facility instrument lunched into $705 \mathrm{~km}$ altitude and covered a period from 1 September 2002 to 29 February 2012.

The $\mathrm{CO}_{2}$ time series is illustrated in Fig. 7 at four selected stations in Siberia (Turukhansky), North Alaska (Sagwon) and two more stations in Canada (Yukon and East of Hudson Bay), where reliable in situ data are available for the same time span as GRACE data. $\mathrm{CO}_{2}$ variations at these four

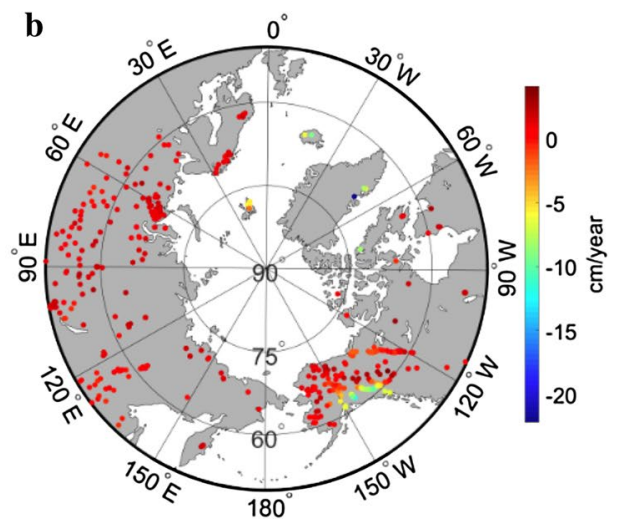

itude region. Blue small circles show locations of selected stations, b shows the distribution (boreholes stations) and secular trend of equivalent water height due to permafrost in the study region

stations are obviously not fully attributed to only the permafrost thawing, but are also affected by different phenomena. The analysis of the $\mathrm{CO}_{2}$ data shows generally positive trend in the study region. The permafrost contains a staggering 850 gigatonnes of frozen carbon (i.e. dry ice) that is much more than the total of the carbon currently contained in the earth's atmosphere, much of which could be released in the form of methane (https://nsidc.org/cryosphere/frozengrou $\mathrm{nd} /$ methane.html). Temperature, $\mathrm{CO}_{2}$ and methane changes are capable of retaining heat in the atmosphere that may accelerate the possibility of catastrophic global warming (cf. Schaefer et al. 2011). It was confirmed by several studies that thawing soils due to permafrost active layer are now the causes pouring carbon dioxide into the air.

The secular trends in $\mathrm{CO}_{2}$ and soil temperature (provided via NOAH-GLDAS) were extracted for the study region and compared with the EWHP obtained from GRACE (see Fig. 8). The slope of linear trend of the EWHP, soil surface temperature and $\mathrm{CO}_{2}$ at selected stations is summarized in Table 2. The result shows that the secular trends at all stations are rising, with a relatively small increase in the soil surface temperature corresponding to relatively large secular trends in the EWHP and $\mathrm{CO}_{2}$.

Table 2 Secular trends of EWHP, average surface temperature and $\mathrm{CO}_{2}$ at selected stations

\begin{tabular}{lllll}
\hline Location & EWHP $(\mathrm{cm} /$ year $)$ & $\begin{array}{l}\text { Soil surface temperature } \\
\left({ }^{\circ} \text { C/year }\right)\end{array}$ & $\begin{array}{l}\text { Soil surface temperature }(\mathrm{Celsius} \\
\text { within 100 years })\end{array}$ & $\mathrm{CO}_{2}(\mathrm{PPM})$ \\
\hline Siberia (Turukhansky) & +3.4 & +0.013 & +1.2 & 2.31 \\
North Alaska (Sagwon) & +3.8 & +0.081 & +8.1 & 2.16 \\
Canada (Yukon) & +4.4 & -0.114 & -11.4 & 2.21 \\
Canada (Hudson Bay, Nunavut) & +4.0 & +0.050 & +5.0 & 2.20 \\
\hline
\end{tabular}



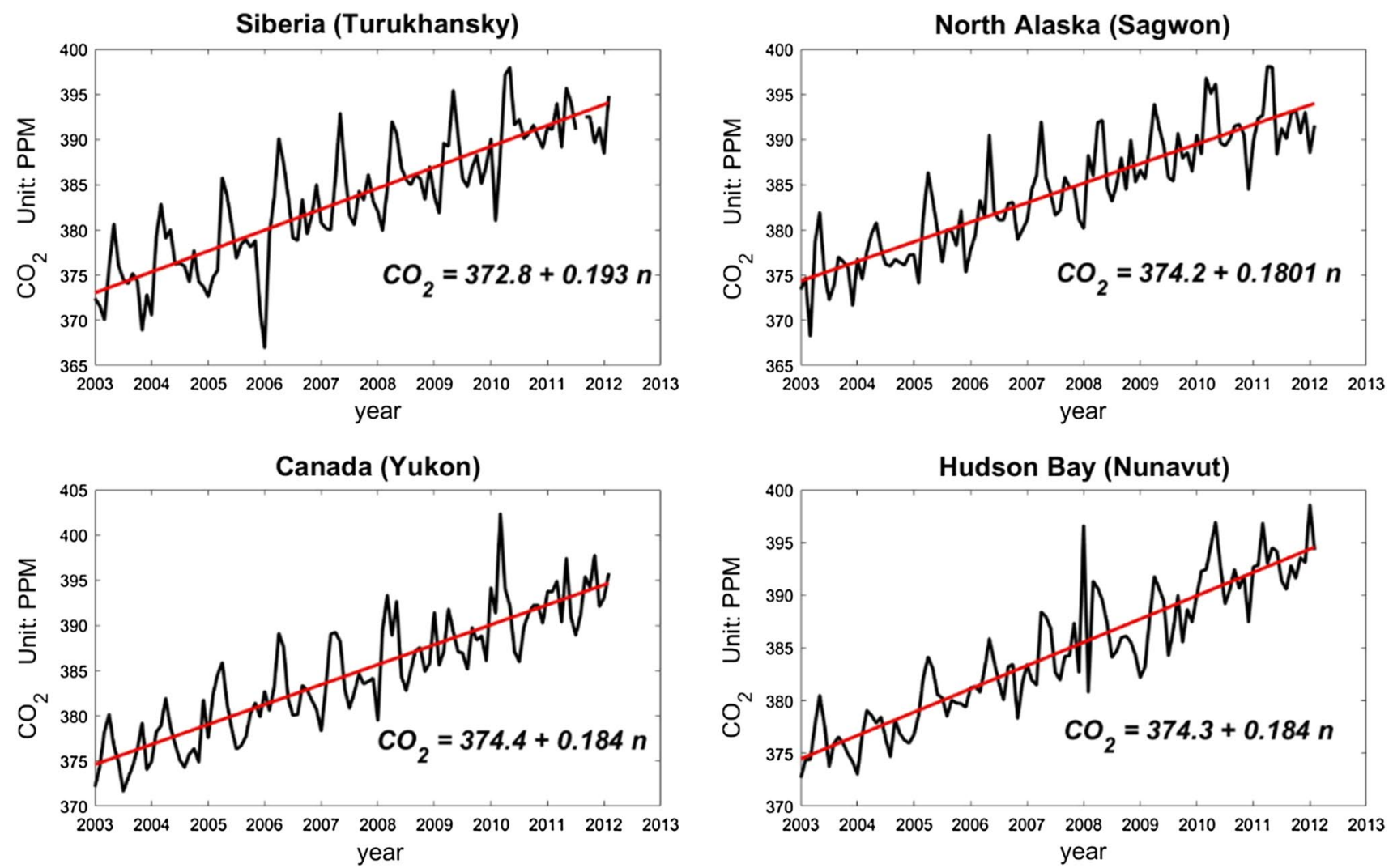

Fig. 7 Carbon dioxide $\left(\mathrm{CO}_{2}\right)$ trend at selected stations in the study region. Note that " $n$ " denotes on the number of months from initial epoch

\section{Discussion}

The permafrost plays important role also in present-day processes related to the earth's system, because there is a good data record suitable for studying the long-term characteristics of this phenomenon. In this study, we focused on a large-scale permafrost monitoring as well as an identification of permafrost hotspots using GRACE monthly solutions. However, these data required the application of additional corrections in order to achieve reliable and accurate products. We studied the permafrost thawing according to Eq. (11) by applying two numerical steps. Firstly, we removed the GIA effect from TWS obtained from GRACE data. This correction was computed according to the ICE6G (VM5a) model (Peltier and Argus 2015). In this step, the role of GIA in the permafrost thawing determination is a vital issue to derive the EWHP secular trend. It is thus important to choose the most accurate GIA model; see an overview of different GIA models in Huang (2013). Our test results, not shown herein, revealed that the ICE-6G (VM5a) model has the best RMS fit with the GPS velocity rates in Fennoscandia and Laurentia. We further used the GLDAS data to investigate and remove the effect of various hydrological contributions in the EWHP modelling. By analogy with the role of GIA model in the EWHP determination, it is also important to study and choose the best and most precise hydrological model that we did not focus on this matter in this paper. Other large-scale lithospheric motions, such as tide effects, will not affect our results due to their periodic character. Moreover, most of these periodic motions have already been removed from the GRACE data.

The EWHP map in Fig. 6a revealed the gravity signature of which pattern corresponds with a total ground water change due to the permafrost layer thawing. Negative values prevail over regions with glacial cover where the ice masses are decreasing (Greenland and Alaska), while other areas are dominated by positive values (i.e. increasing equivalent water storage). A possible method to overcome this issue (i.e. problem of removing the effect of ice melting from EWHP in Fig. 4b) is to use external ice data information such as ICESat data. However, even after removing the surface mass change obtained from ICESat data, a strong negative ice-melting effect in Greenland and Alaska still remains. This ice-melting signal is stronger than the permafrost active layer signal particularly in Greenland and Alaska. Possible reasons for ice melting involve global warming, seasonal and inter-annual periodic signals and warm winds from oceans towards continents. The ice-melting effect is remained even after correcting TWS using ICESat data in the EWHP 

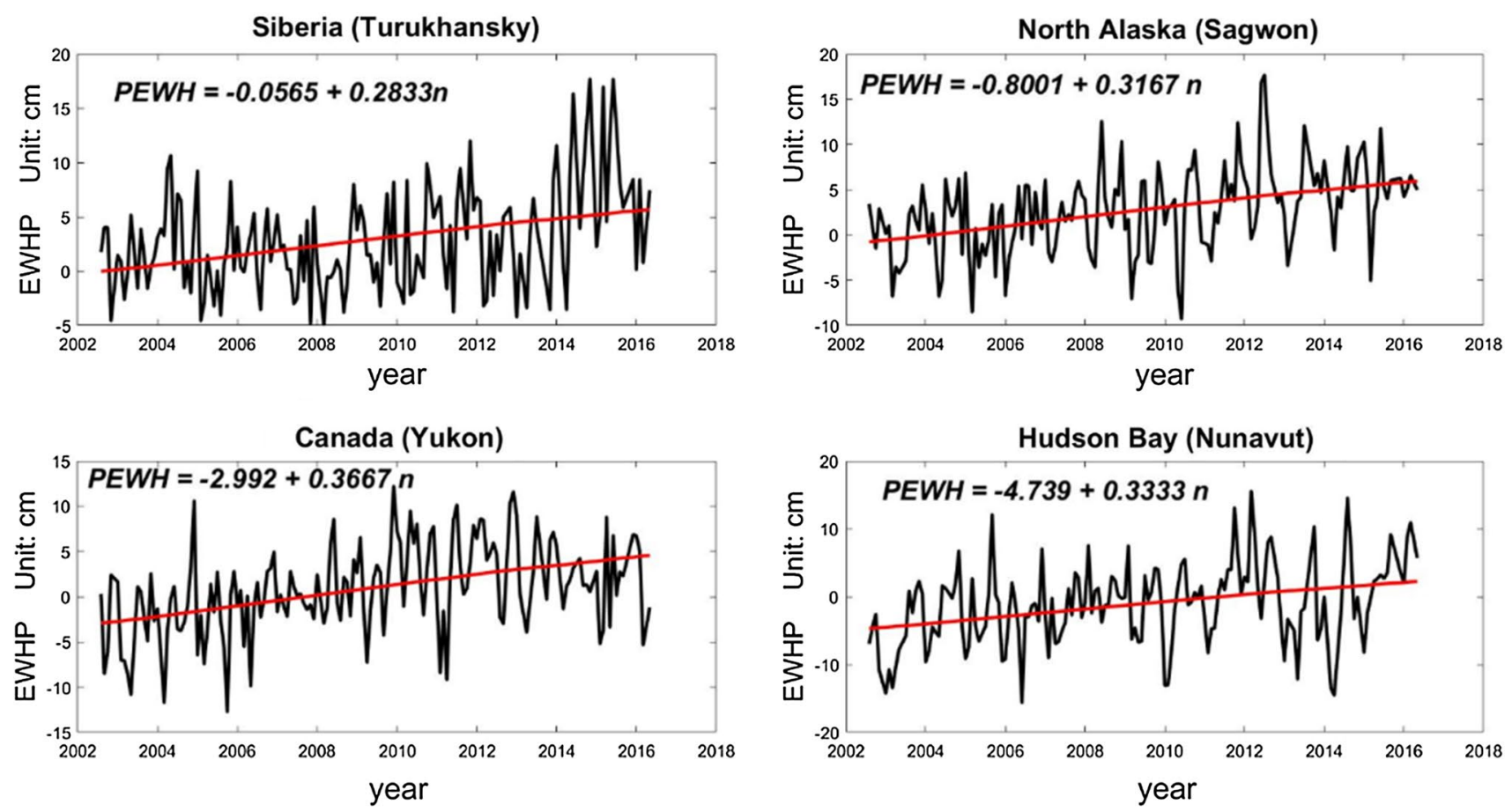

Fig. 8 Equivalent water height due to permafrost (EWHP) time series at selected stations in the study area. Note that " $n$ " denotes the number of months since the initial epoch

(Fig. 6a), because the ICESat measures only a surface mass change instead of a mass change in deeper layers.

According to the calculated EWHP values in the northern high-latitude region, our results and those from the other studies are similar. For example see Velicogna et al. (2012) and Shabanloui and Müller (2015). We find that the EWHP varies from 2 to $4 \mathrm{~cm} /$ year. Shabanloui and Müller (2015) studied the permafrost thawing in Siberia based on GRACE solutions and GLDAS model. They reported that the time series as well as secular trends of GLDAS hydrological mass variations are similar to GRACE results, but in some periods of time differences are obvious. The permafrost thawing dynamics and geophysical processes are very complex. However, we should emphasize that the permafrost is a phenomenon that cannot be associated only with the presence of underground ice. Its degradation is not only the melting of the ice. We also observed differences between the GRACE and GLDAS time series that might be explained by permafrost thawing effects not modelled in GLDAS. Therefore, GLDAS does not include permafrost contributions and it shows the precipitation and surface water masses. Hence, the estimated positive secular trends for the GRACE minus GLDAS results during the period of 2002-2016 may show that the permafrost thawing is progressing in the target region. This is the reason why we removed soil moisture, canopy and river run-off (obtained using GLDAS model) from GRACE observations in order to model the permafrost thawing more realistically. In addition, it should be emphasized that our obtained results using GRACE data are preliminary and can be improved if one combines it with in situ data (e.g. using the published data in the Global Terrestrial Network for Permafrost (GTN- P)). It is also worth mentioning that it would be possible to determine the uncertainty of EWHP, if we had access to all errors in Eq. (11). Only the accuracies of the harmonic coefficients are available for the GRACE data.

The surface temperature is a main component in the climate change and permafrost carbon feedback processes. The obtained soil surface temperature (from GLDAS) varies from -3 to $3{ }^{\circ} \mathrm{C} /$ year in the study region and it shows generally positive trend with a maximum impact in the northern part of Canada (see Fig. 5e). Few scattered areas include small parts in Greenland, and Canada has a negative temperature trend. Three locations out of the four selected stations show positive trend ranged from +0.013 to $+0.081^{\circ} \mathrm{C} /$ year, and one shows average negative trend of $-0.114{ }^{\circ} \mathrm{C} /$ year (see Table 2). Therefore, as the air and soil temperature rose over time, the active layer part of the permafrost and the permafrost temperature will increase forming a talik layer, where the permafrost top part remains at $0^{\circ} \mathrm{C}$ and the bottom of the active layer froze/melt seasonally.

The $\mathrm{CO}_{2}$ analysis shows a positive trend all over the study region, ranging from 1.9 to $2.5 \mathrm{PPM} / \mathrm{year}$. The trend for the selective stations ranges from 2.16 to 2.31 PPM/ 

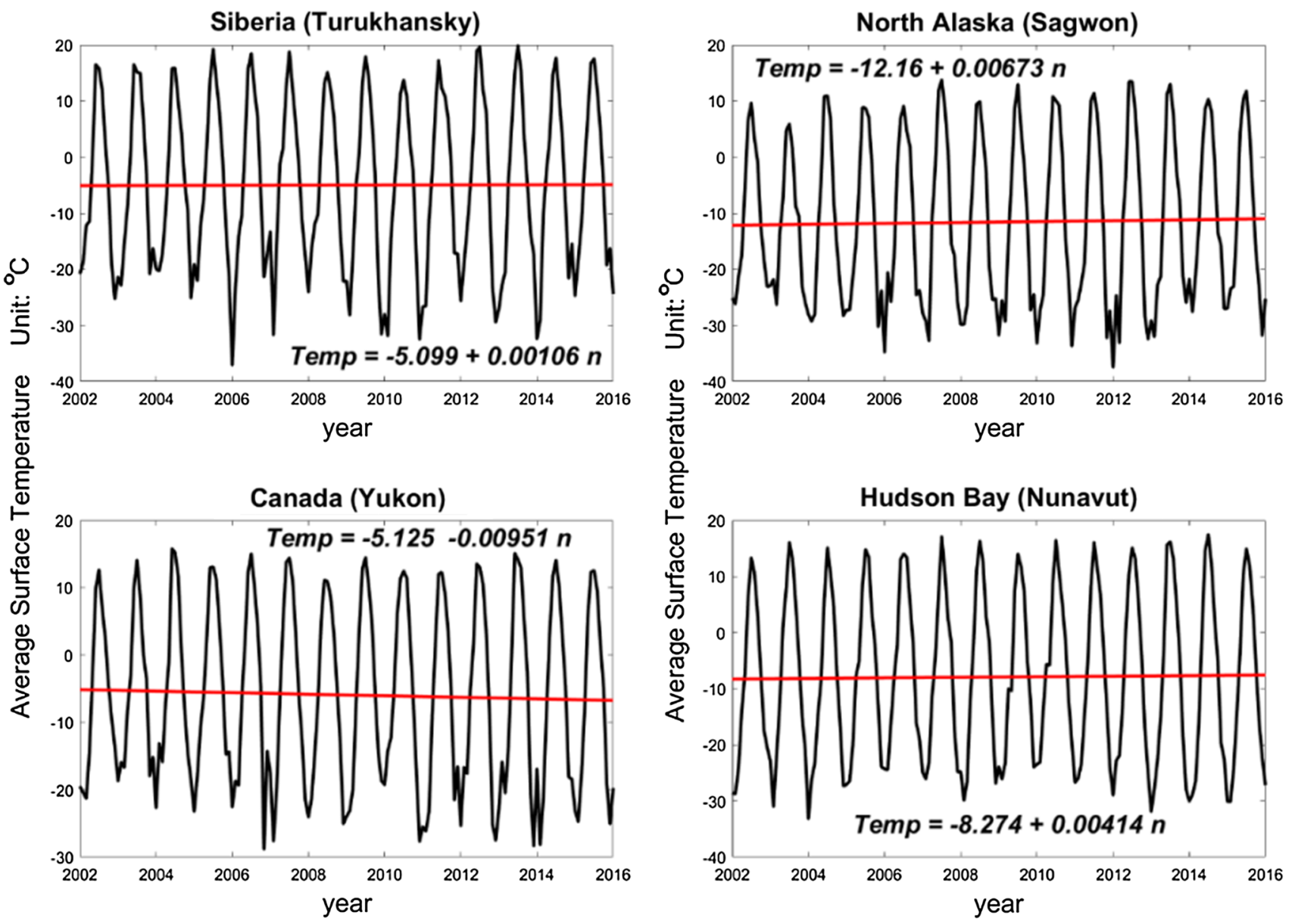

Fig. 9 Soil surface temperature time series at selected stations in the study region. Note that " $n$ " denotes the number of months from initial epoch

year. Our results show that $\mathrm{CO}_{2}$ increases in average of 2.2 $\mathrm{PPM} / \mathrm{year}$ in the selected regions, and there is correlation between the secular trend of greenhouse gases and the equivalent water height (i.e. EWHP shown in Fig. 8) that is due to the thawing process and temperature increase. Consequently, our results can be used to determine future emissions and the impact of $\mathrm{CO}_{2} /$ methane releases. The comparison of the permafrost equivalent water thickness with $\mathrm{CO}_{2}$ secular trends in Fig. 7 shows that frozen soils (permafrost) are unleashing an increasing amount of $\mathrm{CO}_{2}$ into the air as they thaw in summer or subsequently fail to refreeze as they once did, particularly in late fall and early winter. However, we should emphasize that the release of $\mathrm{CO}_{2}$ in the seasonally frozen layer, i.e. the active layer is sporadically occurring but the biologic processes of release and consumption, is highly variable and not well understood nor measured at sufficient detail and scale for a meaningful conclusion at this time. Our results also indicate an increasing amount of $\mathrm{CO}_{2}$ loss (Fig. 7) as well as an increasing surface temperature at selected stations
(Fig. 9) in late spring and summer as the climate warmest steadily. Obviously, the large areas of permafrost in Canada and Siberia are partially responsible for some of the carbon dioxide emissions into the atmosphere. Since the Carbon dioxide can originate from anywhere on the Earth, proving that the carbon is coming from the thawed permafrost need special measuring tool and looking at the isotopic signatures to see that the carbon is old or coming from recent carbon cycling. Schaefer et al. (2012) stated that permafrost carbon starts thawing when the active layer exceeds certain thickness in the warm year. Therefore, in our case we conclude that the obtained $\mathrm{CO}_{2}$ could be partially or completely from the thawed permafrost.

\section{Conclusions}

We have used monthly GRACE data, GIA and GLDAS models to study the groundwater storage change and permafrost thawing in the northern high-latitude region. The used time series covered the period from August 2002 
to May 2016. Subtracting the GIA effect and hydrological water cycle contribution from the total water storage obtained using GRACE data reveals changes in the groundwater storage. Our result shows that the GIA effect is significant for determining the water storage change. We postulate that these water storage changes can be related to the permafrost thawing. We obtained negative values of the equivalent water height in Greenland and Alaska regions and we removed these effects from the groundwater storage using ICESat data. Permafrost thawing might be detected with positive values of the equivalent water height, and it quantifies the increase in the ground water storage. We showed that the ground water storage is changing by up to 3.4, 3.8, 4.4 and $4.0 \mathrm{~cm} /$ year in Siberia, North of Alaska and Canada (Yukon and Hudson Bay), respectively, most probably due to permafrost thawing using GRACE, GLDAS and ice-melting data. We also illustrated those greenhouse gases, i.e. carbon dioxide $\left(\mathrm{CO}_{2}\right)$ and methane, increased up to $2.2 \mathrm{PPM} /$ year in the study areas over the same period. Temperature also shows positive trend generally and in the study area as well as $\mathrm{CO}_{2}$ and equivalent water height trend (due to permafrost thawing) which might confirm the permafrost carbon feedback process.

Acknowledgements Shfaqat A. Khan from DTU Space, National Space Institute, Technical University of Denmark, Department of Geodesy is cordially acknowledged for preparing ICESat data for this study. Also, the first author would like to thank Faramarz Nilfouroushan, University of Gävle, Sweden, for his great support.

Open Access This article is distributed under the terms of the Creative Commons Attribution 4.0 International License (http://creativeco mmons.org/licenses/by/4.0/), which permits unrestricted use, distribution, and reproduction in any medium, provided you give appropriate credit to the original author(s) and the source, provide a link to the Creative Commons license, and indicate if changes were made.

\section{References}

Ågren J, Svensson R (2007) Postglacial land uplift model and system definition for the new Swedish height system RH 2000. Reports in geodesy and geographical information systems, LMV-Rapport:4. Lantmäteriet, Gävle, Sweden

Bevis M, Melini D, Spada G (2016) On computing the geoelastic response to a disk load. Geophys J Int 205(3):1804-1812. https:// doi.org/10.1093/gji/ggw115

Biskaborn BK, Lanckman JP, Lantuit H, Elger K, Streletskiy DA, Cable WL, Romanovsky VE (2015) The global terrestrial network for permafrost database: metadata statistics and prospective analysis on future permafrost temperature and active layer depth monitoring site distribution. Earth Syst Sci Data Discuss 8:279-315

Brown J, Ferrians OJ, Heginbottom JA, Melnikov ES (1998) CircumArctic map of permafrost and ground-ice conditions. Boulder, CO: National Snow and Ice Data Center/World Data Center for Glaciology. Digital Media
Brown J, Hinkel KM, Nelson FE (2000) The circumpolar active layer monitoring (CALM) program: research designs and initial results. Polar Geogr 24:165-258

Chao BF, Wu YH, Zhang Z, Ogawa R (2011) Gravity bariation in Siberia: GRACE observation and possible causes. Terr Atmos Ocean Sci 22:149-155. https://doi.org/10.3319/tao.2010.07.26.03(tibxs)

Chen F, Mitchell K, Schaake J, Xue Y, Pan H, Koren V, Duan Y, Ek M, Betts A (1996) Modeling of land-surface evaporation by four schemes and comparison with FIFE observations. J Geophys Res 101(D3):7251-7268

Ekman M (1991) A concise history of postglacial land uplift research (from its beginning to 1950). Terra Nova 3:358-365

Farrell WE (1972) Deformation of the Earth by surface loading. Rev Geophys 10:761-797

Frauenfeld OW, Zhang T, Barry RG, Gilichinsky D (2004) Interdecadal changes in seasonal freeze and thaw depths in Russia. J Geophys Res. https://doi.org/10.1029/2003jd004245

French HM (2013) The periglacial environment. John Wiley \& Sons, Hoboken

Han S-C, Shum CK, Jekeli C, Kuo C-Y, Wilson C, Seo K-W (2005) Non-isotropic filtering of GRACE temporal gravity for geophysical signal enhancement. Geophys J Int 163:18-25. https://doi. org/10.1111/j.1365-246x.2005.02756

Huang Z (2013) The role of glacial isostatic adjustment (GIA) process on the determination of present-day sea-level rise. Report No. 504. Geodetic Science The Ohio State University Columbus, Ohio. 43210 October

Hugelius G, Virtanen T, Kaverin D, Pastukhov A, Rivkin F, Marchenko S, Romanovsky V, Kuhry P (2011) High-resolution mapping of ecosystem carbon storage and potential effects of permafrost thaw in periglacial terrain, European Russian Arctic. J Geophys Res Biogeosci 116:G03024. https://doi.org/10.1029/2010JG001606

Joud SM, Sjöberg LE, Bagherbandi M (2017) Use of GRACE data to detect the present land uplift rate in Fennoscandia. Geophys J Int 209(2):909-922. https://doi.org/10.1093/gji/ggx063

Khan SA, Kjær KH, Bevis M, Bamber JL, Wahr J, Kjeldsen KK, Bjørk AA, Korsgaard NJ, Stearns LA, van den Broeke MR, Liu L, Larsen NK, Muresan IS (2014) Sustained mass loss of the Northeast Greenland ice sheet triggered by regional warming. Nat Clim Chang 4:292-299. https://doi.org/10.1038/nclimate2161

Klees R, Revtova EA, Gunter BC, Ditmar P, Oudman E, Winsemius HC, Savenije HHG (2008) The design of an optimal filter for monthly GRACE gravity models. Geophys J Int 175:417-432. https://doi.org/10.1111/j.1365-246x.2008.03922.x

Koren V, Schaake J, Mitchell K, Duan QY, Chen F, Baker JM (1999) A parameterization of snowpack and frozen ground intended for NCEP weather and climate models. J Geophys Res 104:19569-19585

Koven DC, Ringeval B, Friedlingstein P, Ciais P, Cadule P, Khvorostyanov D, Krinner G, Tarnocai C (2011) Permafrost carbon-climate feedbacks accelerate global warming. PNAS2011 108(36):1476914774. https://doi.org/10.1073/pnas. 1103910108

Kusche J (2007) Approximate decorrelation and non-isotropic smoothing of time-variable GRACE-type gravity field models. J Geodesy 81(11):733-749

Kusche J, Schmidt R, Petrovic S, Rietbroek R (2009) Decorrelated GRACE time-variable gravity solutions by GFZ, and their validation using a hydrological model. J Geodesy. https://doi. org/10.1007/s00190-009-0308-3

Lawrence DM, Koven CD, Swenson SC, Riley WJ, Slater AG (2015) Permafrost thaw and resulting soil moisture changes regulate projected high-latitude $\mathrm{CO} 2$ and $\mathrm{CH} 4$ emissions. Environ Res Lett. https://doi.org/10.1088/1748-9326/10/9/094011

Lemke P, Ren J, Alley RB, Allison I, Carrasco J, et al. (2007) Observations: changes in snow, ice and frozen ground. In: Solomon S, Qin 
D, Manning M, Chen Z, Marquis M, et al. (eds) Climate change 2007: the physical science asis. Contribution of working group I to the fourth assessment report of the Intergovernmental panel on climate change. Cambridge University Press, Cambridge, UK and New York, NY, USA

Lemoine FG, Luthcke SB, Rowlands DD, Chinn DS, Klosko SM, Cox CM (2007) The use of mascons to resolve time-variable gravity GRACE. In: Tregoning P, Rizos C (eds) Dynamic planet: monitoring and understanding a dynamic planet with geodetic and oceanographic tools. Springer, Berlin, pp 231-236. ISBN 978-3-540-49349-5

Liu L, Zhang T, Wahr J (2010) InSAR measurements of surface deformation over permafrost on the North Slope of Alaska. J Geophys Res 115:F03023. https://doi.org/10.1029/2009jf001547

Moore P, Zhang Q, Alothman A (2005) Annual and semiannual variations of the Earth's gravitational field from satellite laser ranging and CHAMP. J Geophys Res. https://doi.org/10.1029/2004j b003448

Muskett RR, Romanovsky VE (2009) Groundwater storage changes in Arctic permafrost watersheds from GRACE and in-situ measurements. Environ Res Lett 4(4):045009

Muskett RR, Romanovsky VE (2011) Alaskan permafrost groundwater storage changes derived from grace and ground measurements. Remote Sens 3:378-397. https://doi.org/10.3390/rs3020378

Osterkamp TE (2007) Characteristics of the recent warming of permafrost in Alaska. J Geophys Res. https://doi.org/10.1029/2006j f0005788

Peltier WR (2004) Global glacial isostasy and the surface of the ice-age Earth: the ICE-5G (VM2) model and GRACE, invited paper. Ann Rev Earth Planet Sci 32:111-149

Peltier WR, Argus DF (2015) Drummond, R. Space geodesy constrains ice-age terminal deglaciation: the global ICE-6G_C VM5a model. J Geophys Res Solid Earth 120:450-487. https:// doi.org/10.1002/2014jb011176

Phillips M, Springman SM, Arenson LU (eds) (2003) Proceedings of the eighth international conference on permafrost, Zurich, Switzerland, 21-25 July, vol 1 and 2. A.A. Balkema, Lisse, The Netherlands, $1319 \mathrm{p}$

Rodell M, Famiglietti JS, Chen J, Seneviratne SI, Viterbo P, Holl S, Wilson CR (2004) Basin scale estimates of evapotranspiration using GRACE and other observations. Geophys Res Lett. https:// doi.org/10.1029/2004GL020873

Schaefer K, Zhang T, Bruhwiler L, Barrett AP (2011) Amount and timing of permafrost carbon release in response to climate warming. Tellus B 63:165-180. https://doi.org/10.111 1/j.1600-0889.2011.00527.x

Schaefer K, Lantuit H, Romanovsky V, Schuur EAG (2012) Policy implications of warming permafrost. United Nations Environment Programme Special Report, Nairobi, Kenya, p 50

Schuur EAG, Vogel JG, Crummer KG, Lee H, Sickman JO, Osterkamp TE (2009) The effect of permafrost thaw on old carbon release and net carbon exchange from tundra. Nature 459:556-559

Shabanloui A, Müller J (2015) Mass variations in the siberian permafrost region based on new GRACE results and auxiliary modeling. In: International association of geodesy symposia. Springer International Publishing Switzerland. https://doi. org/10.1007/1345_2015_186

Sjöberg LE, Bagherbandi M (2017) Gravity inversion and integration: theory and applications in geodesy and geophysics. Springer, Berlin
Sjöberg Y, Frampton A, Lyon S (2013) Using streamflow characteristics to explore permafrost thawing in northern Sweden. Hydrogeol J 21(1):121-131. https://doi.org/10.1007/s10040-012-0932-5

Smith NV, Saatchi SS, Randerson T (2004) Trends in high latitude soil freeze and thaw cycles from 1988 to 2002 . J Geophys Res. https ://doi.org/10.1029/2003jd004472

Steffen H, Müller J, Peterseim N (2012) Mass variations in the Siberian permafrost region from GRACE. In: Kenyon S, Pacino MC, Marti U (eds) Geodesy for planet earth, vol 136. Springer, Berlin, pp 597-603

Sun W, Sjöberg LE (1999) Gravitational potential changes of a spherically symmetric earth model caused by a surface load. Geophys J Int 137:449-468

Swenson S, Wahr J (2006) Post-processing removal of correlated errors in GRACE data. Geophys Res Lett 33:L08402. https://doi. org/10.1029/2005gl025285

Swenson S, Wahr J, Milly PCD (2003) Estimated accuracies of regional water storage variations inferred from the gravity recovery and climate experiment (GRACE). Water Resour Res 39:1223. https ://doi.org/10.1029/2002wr001808

Tapley BD, Bettadpur S, Watkins M, Reigber C (2004) The gravity recovery and climate experiment: mission overview and early results. Geophys Res Lett 31:L09607. https://doi. org/10.1029/2004GL019920

Treat CC, Wollheim WM, Varner RK, Grandy AS, Talbot J, Frolking S (2014) Temperature and peat type control co2 and ch4 production in Alaskan permafrost peats. Glob Chang Biol 20(8):2674-2686. https://doi.org/10.1111/gcb.12572

Velicogna I, Tong J, Zhang T, Kimball JS (2012) Increasing subsurface water storage in discontinuous permafrost areas of the Lena river basin, Eurasia, detected from GRACE. Geophys Res Lett. https ://doi.org/10.1029/2012g1051623

Vey S, Steffen H, Müller J, Boike J (2013) Inter-annual water mass variations from GRACE in central Siberia. J Geodesy 87(3):287-299

Wahr J, Molenaar M, Bryan F (1998) Time variability of the Earth's gravity field: hydrological and oceanic effects and their possible detection using GRACE. J Geophys Res Solid Earth 103(B12):30205-30229

Wahr J, Swenson S, Zlotnicki V, Velicogna I (2004) Time-variable gravity from GRACE: first results. Geophys Res Lett 31(11):L11501. https://doi.org/10.1029/2004GL019779

Wouters B, Schrama EJO (2007) Improved accuracy of GRACE gravity solutions through empirical orthogonal function filtering of spherical harmonics. Geophys Res Lett 34:L23711. https://doi. org/10.1029/2007gl032098

Wu Q, Zhang T (2010) Changes in active layer thickness over the Qinghai Tibetan Plateau from 1995 to 2007. J Geophys Res 115:D09107. https://doi.org/10.1029/2009jd012974

Yang Z, Gao J, Zhao L, Xu X, Ouyang H (2013) Linking thaw depth with soil moisture and plant community composition: effects of permafrost degradation on alpine ecosystems on the Qinghai-Tibet plateau. Plant Soil 367(1-2):687-700. https://doi.org/10.1007/ s11104-012-1511-1

Zech M, Zech R, Zech W, Glaser B, Brodowski S, Amelung W (2008) Haracterisation and palaeoclimate of a loess-like permafrost palaeosol sequence in NE Siberia. Geoderma 143:281-295

Zhang T, Frauenfeld OW, Serreze MC, Etringer A, Oelke C et al (2005) Spatial and temporal variability in active layer thickness over the Russian Arctic drainage basin. J Geophys Res 110:1-9. https:// doi.org/10.1029/2004jd005642 